\title{
The Linguistic Representation of Iranian and Western Actors of Iran's Nuclear Program in International Media: A CDA Study
}

\author{
Reza Kheirabadi \\ Department of Linguistics, Tarbiat Modares University, Tehran, Iran \\ Email: rkheirabadi@gmail.com \\ Sayyed Behnam Alavi Moghaddam \\ Organization for Educational Research and Planning (OERP), Tehran, Iran \\ Email: behnam_9002@yahoo.com
}

\begin{abstract}
Revealing the unequal relation of power which leads to hegemony in mass media and making audiences aware of this unequal representation of events have been in the center of attention for Critical Discourse Analysis (CDA) for a long period of time. As Fairclough states becoming aware of this complicated process of manipulation of reality through linguistic mechanisms will " help increase consciousness of how language contributes to the domination of some people by others, because consciousness is the first step towards emancipation." ( 2001, p.1) van Leeuwen's (2008) socio-semantic network of social actors is been considered as a competent framework for linguists and discourse analysts to do so. In this article, we study 50 hard news and articles published in leading international news agencies and newspapers about Iran's nuclear program during November and December 2010 to analyze the way the social actors of both sides of the quarrel have been represented in the media. The results showed that although the international news agencies and newspapers claim to stay neutral in representing the events, some linguistic mechanisms to represent Iranian social actors differently from the western ones are obvious and Iranian social actors playing role in this case are shown as irrational hardliners while western counterparts are introduced as logical peace seeker ones.
\end{abstract}

Index Terms-Critical Discourse Analysis (CDA), Iran's nuclear case, socio-semantic network of social actors, van Leeuwen

\section{INTRODUCTION}

The history of linguistic analysis of news as discourse mainly goes back to van Dijk's pioneering work (1988). He starts his discussion from the ambiguity of the notion of the news and illustrates three different commonly accepted definitions of the news and writes: "The notion of news is ambiguous. First, we have the general notion of news, meaning 'new information', as we find in such everyday sentences as "I have had news for you" or "What is the latest news from your son?"

Clearly, the notion of news we are dealing with is both different but also has meaning components in common with this more general notion. Our notion of news, then, is part of a second class of meanings, which involve the media and mass communication. It is used in such expressions as "Have you read the news about the rising interest rate"? or in "Did you watch the news last night"? Even this class of media news notions contains interesting ambiguity.

...In other words, the notion of media news in everyday usage implies the following concepts:

1. New information about events, things or persons.

2. A (TV or radio) program type in which news items are presented.

3. A news item or news report, i.e., a text or discourse on radio, on TV or in the newspaper, in which new information is given about recent events. (pp. 3-4)

The development of critical studies of language leads to further explorations on the nature of the news and the connections between language and the news. Many linguistic works such as Fowler (1991), Fairclough (1989, 2001) Fowler (1991) and van Dijk (1988) were published to show the linguistic mechanisms of manipulation of the real world events by journalists. Fairclough (2001, p.1) elaborates his aims to wite the book as "I have written it for two purposes. The first is more theoretical: to help correct a widespread underestimation of significance of language in the production, maintenance, and change of social relations of power. The second is more practical: to help increase consciousness of how language contributes to the domination of some people by others, because consciousness is the first step towards emancipation."

Each of these linguistic attempts has its own theoretical and practical privileges and weak points. Some of them are mainly centered around formal linguistics concepts (for example Fowler, 1991) but almost all of them have paid have 
shown clear interest to functional approach to text analysis (mainly M.A.K Haliday's Systemic Functional Grammar) as a dynamic approach to text analysis which goes beyond the limitations of Chomsky's generative grammar.

Van Leeuwen's socio-semantic approach to text analysis is one of the most frequently cited frameworks within CDA and many researches have been done using its theoretical concepts to describe the social and semantic features of the representation of the social actors in a social interaction. This framework has been also used to analyze media discourses. In the following section we initially review basic concepts of this framework.

\section{THEORETICAL FRAMEWORK: VAN LEEUWEN's SOCIO-SEMANTIC NETWORK OF SOCIAL ACTORS}

Van Leeuwen initiates the discussion by the key illustration of the representations of social actors and writes: "My question, "How can social actors be represented in English?" is a grammatical question if, with Halliday, we take a grammar to be a "meaning potential" ("what can be said") rather than a set of rules ("what must be said"). Yet, unlike many other linguis tically oriented forms of critical discourse analysis, I will not start out from linguistic operations, such as nominalization and passive agent deletion, or from linguistic categories, such as the categories of transitivity, but instead will draw up a socio-semantic inventory of the ways in which social actors can be represented and establish the sociological and critical relevance of my categories before I turn to the question of how they are realized linguistically." (van Leeuwen,2008, p.23)

The socio-semantic network of social actors is divided into two main branches of 1) exclusion and 2) inclusion as van Leeuwen mentions: "Representations include or exclude social actors to suit their interests and purposes in relation to the readers for whom they are intended." (ibid:28) Exclusion means omitting actors of a social action by some linguistic mechanisms and has two main subdivisions: suppression and backgrounding. As van Leeuwen mentions "Exclusion has rightly been an important aspect of critical discourse analysis. To mention just one classic example, Tony Trew (1979: 97ff.) showed how, in the Times and the Rhodesian Herald (during the year 1975), the police were excluded in accounts of the "riots" during which they had opened fire and killed demonstrators, because it was in the interest of these papers and their readers to attempt to justify white rule in Africa". (ibid)

The main distinguishable difference between suppression and backgrounding is the point that they leave trace or not.

In other words Some exclusions leave no traces in the representation, excluding both the social actors and their activities. Such radical exclusion can play a role in a critical comparison of different representations of the same social practice, but not in an analysis of a single text, for the simple reason that it leaves no traces behind. This radically exclusion without leaving clear traces within the text is called suppression while in backgrounding the exclusion process does leave some traces but actors are excluded to provide the interests of the newspaper or text in general, van Leeuwen himself elaborates the discussion and writes: "When the relevant actions (e.g., the killing of demonstrators) are included, but some or all of the actors involved in them (e.g., the police) are excluded, the exclusion does leave a trace. We can ask "But who did the killing?" or "But who was killed?" even though the text does not provide the answers. In this case, a further distinction should perhaps be made, the distinction between suppression and backgrounding. In the case of suppression, there is no reference to the social actor(s) in question anywhere in the text." (p.29)

It worth to mention that in most cases it is not easy to say if the exclusion process leaves any trace and the omitted actors are retrievable by the readers or not.

Some of the linguistic signs of suppression are passive agent deletion (in an expression such as "many concerns are being expressed about this problem" by whom is not clear) and nonfinite clauses which function as a grammatical Participant (such as "To maintain this policy is hard." in which nonfinite clause of to maintain policy plays the role of one of the grammatical participants of the action expressed in the sentence.)

To delete beneficiaries of an action is another mechanism of exclusion. In the following text, social actors who benefit from the action (probably Pakistanis who had been offended) are deleted from the text:

“Japan's National Police Agency had to apologise recently for circulating an internal memo to police stations claiming that Pakistanis working in Japan have a unique body odour, carry infectious skin diseases and tell lies under the name of Allah."

Van Leeuwen enumerates some of the linguistic representations of backgrounding and writes: " Backgrounding can result from simple ellipses in nonfinite clauses with -ing and -ed participles, in infinitival clauses with to, and in paratactic clauses. In all of these cases, the excluded social actor is included elsewhere in the same clause or clause complex. It can also be realized in the same way as suppression, but with respect to social actors who are included elsewhere in the text. The two realizations background social actors to different degrees, but both play a part in reducing the number of times specific social actors are explicitly referred to." (p. 30-31)

The distinction between generic and specific (Genericization versus Specification) reference is also important in the representation of social actors; they can be represented as classes, or as specific identifiable individuals. Genericization may be realized by the plural without article such as "Iranian students" in the following sentence:

"Iranian students are among the most successful students of the international universities."

If social actors are represented as individuals, it is called "individualization" but if they are shown as groups it is labeled as assimilation. As van Leeuwen exemplifies: 
"Individualization is realized by singularity and assimilation by plurality, as with "Australians" and "Muslims" in 2.28:

2.28 Australians tend to be skeptical about admitting "Muslims."

Alternatively, assimilation may be realized by a mass noun or a noun denoting a group of people as, for instance, with "this nation" in 2.29 and "the community" in 2.30 :

2.29 Is he [Prime Minister Hawke] entitled to believe that this nation, which only recently shed the White Australia Policy, is somehow impervious to racist sentiment?

Association versus dissociation is another important distinctive dichotomy in van Leeuwen network of social actors: "There is another way in which social actors can be represented as groups: association. Association, in the sense in which I shall use the term here, refers to groups formed by social actors and/or groups of social actors (either generically or specifically referred to) which are never labeled in the text (although the actors or groups who make up the association may of course themselves be named and/or categorized). The most common realization of association is parataxis" (p.38)

Nomination and categorization are two other important notions in this network. When social actors are presented in terms of their unique identity, they are nominated and when they are represented in terms of their common identities and functions they are categorized.

In inclusion, we generally face a process in which the interested actors are put in the center of attention and presented in the text clearly. Inclusion is a more diversified process in van Leeuwen's network and in the first level of distinction can be divided into three subparts of:

-Activation / passivation

- Participation / Circumstantialization / Possessivation

- Personalization / Impersonalization

\section{DATA AND Methodology}

The data of this article is a body of 50 hard news and article which are selected from leading international media to study the way they represent Iranian and western actors, playing role in Islamic Republic of Iran's nuclear case. These articles were published in time span of November and December of 2010 and are selected from the large number of analyses and news items published to cover the nuclear clash between Islamic Republic of Iran and major European countries plus the United States of America which are generally called as major world powers by international media. We try to analyze this body of news discourse within van Leeuwen's socio-semantic network of social actors and testify the level of neutrality of the international media in covering the news relating to this international clash. We will mainly focus on two major mechanisms of inclusion and exclusion in the body of selected news to see which actors are in the center of attention and which are backgrounded or totally suppressed. The following table shows the articles and news selected to study in this paper: 
TABLE 1

TITLES AND SOURCES OF THE NEWS ARTICLES

\begin{tabular}{|c|c|c|c|}
\hline No. & Title & Date & Source \\
\hline 1 & Iran says no date set for nuclear talks & Tuesday, 28 December 2010 & Agance France Press(AFP) \\
\hline 2 & Medvedev says Iran nuclear stance 'unreasonably tough' & Wednesday, 22 December 2010 & Bloomberg \\
\hline 3 & Iran atomic chief Salehi takes charge as new FM & Saturday, 18 December 2010 & Agance France Press(AFP) \\
\hline 4 & U.S., EU nations agree on new Iran sanctions & Saturday, 18 December 2010 & The Wall Street Journal \\
\hline 5 & Iran maintains nuclear policy after FM sacked & Tuesday, 14 December 2010 & AFP \\
\hline 6 & Top US officer says Iran still driving for a bomb & Saturday, 18 December 2010 & The Associated Press(AP) \\
\hline 7 & U.S. and allies plan more sanctions against Iran & Saturday, 11 December 2010 & The New York Times \\
\hline 8 & West eyes tighter Iran sanctions for arms smuggling & Friday, 10 December 2010 & AFP \\
\hline 9 & Little progress seen as talks with Iran come to end & Wednesday, 08 December 2010 & The Washington Post \\
\hline 10 & Ahmadinejad sets nuclear red lines for January talks & Wednesday, 08 December 2010 & Reuters \\
\hline 11 & Iran will not discuss atom enrichment at next talks & Tuesday, 07 December 2010 & Reuters \\
\hline 12 & Gulf states urge Iran to be 'positive' on nuclear talks & Tuesday, 07 December 2010 & AFP \\
\hline 13 & Iran talks were difficult: U.S. official & Tuesday, 07 December 2010 & Reuters \\
\hline 14 & Major powers and Iran hold 'constructive' talks & Tuesday, 07 December 2010 & The Washington Post \\
\hline 15 & Scientist's death dominates nuclear talks as Iran blames agents & Monday, 06 December 2010 & Bloomberg \\
\hline 16 & Yellowcake plays a crucial role & Monday, 06 December 2010 & The Wall Street Journal \\
\hline 17 & Iran touts nuclear advance ahead of U.S. talks & Monday, 06 December 2010 & The Wall Street Journal \\
\hline 18 & Nuclear chief says Iran to process own raw uranium & Sunday, 05 December 2010 & The Associated Press \\
\hline 19 & Iran accuses U.N. nuclear agency of sending spies & Sunday, 05 December 2010 & Reuters \\
\hline 20 & Iran ready for talks, but not on nuclear rights: Ahmadinejad & Sunday, 05 December 2010 & AFP \\
\hline 21 & Clinton presses Iranians & Saturday, 04 December 2010 & The Wall Street Journal \\
\hline 22 & China says hopes Iran nuclear talks are constructive & Friday, 03 December 2010 & Reuters \\
\hline 23 & EU powers say Iran on path of "confrontation" & Thursday, 02 December 2010 & Reuters \\
\hline 24 & US lawmakers fume over China's Iran links & Thursday, 02 December 2010 & AFP \\
\hline 25 & Iran talks must focus on nuclear issue: Clinton & Wednesday, 01 December 2010 & Reuters \\
\hline 26 & US hopes Iran will pursue 'serious process' on nuclear issue & Tuesday, 30 November 2010 & AFP \\
\hline 27 & EU's Ashton to hold talks with Iran Dec. 6-7 & Tuesday, 30 November 2010 & Reuters \\
\hline 28 & Embarrassed silence in Gulf over WikiLeaks on Iran & Monday, 29 November 2010 & AFP \\
\hline 29 & Iran admits uranium enrichment hit by malware & Monday, 29 November 2010 & AFP \\
\hline 30 & Iran's atom enrichment not negotiable-Ahmadinejad & Monday, 29 November 2010 & REUTERS \\
\hline 31 & Around the world, distress over Iran & Monday, 29 November 2010 & The New York Times \\
\hline 32 & Iran's nuclear plant starts operationsSaturday & 27 November 2010 & AFP \\
\hline 33 & Centrifuges in Iran were shut down, IAEA report says & Wednesday, 24 November 2010 & The Washington Post \\
\hline 34 & US stresses Iran's ‘continued failure' to comply with IAEA & Wednesday, 24 November 2010 & AFP \\
\hline 35 & Report says computer worm stymied Iran nuclear sites & Wednesday, 24 November 2010 & The Wall Street Journal \\
\hline 36 & Iran denies problem with uranium enrichment & Tuesday, 23 November 2010 & AFP \\
\hline 37 & North Korea nuclear find raises fear on Tehran & Tuesday, 23 November 2010 & The Wall Street Journal \\
\hline 38 & Iran to hike atomic output despite possible talks & Monday, 22 November 2010 & Reuters \\
\hline 39 & Iran nuclear talks likely in Geneva next month: EU & Monday, 22 November 2010 & AFP \\
\hline 40 & Stuxnet may be part of Iran atom woes - ex-IAEA aide & Sunday, 21 November 2010 & Reuters \\
\hline 41 & Worm can deal double blow to nuclear program & Saturday, 20 November 2010 & The New York Times \\
\hline 42 & Russia tells Iran to keep nuclear drive peaceful & Thursday, 18 November 2010 & AFP \\
\hline 43 & Gates says Iran leadership rift over nuclear sanctions & Tuesday, 16 November 2010 & BBC News \\
\hline 44 & Stuxnet study suggests Iran enrichment aim: experts & Tuesday, 16 November 2010 & Reuters \\
\hline 45 & Analysis: Are Iran nuclear talks doomed to fail again? & Monday, 15 November 2010 & Reuters \\
\hline 46 & China, Russia urge Iran to show nuclear plans peaceful & Monday, 15 November 2010 & Reuters \\
\hline 47 & Iran's nuke plant to feed power grid in December & Sunday, 14 November 2010 & The Associated Press \\
\hline 48 & Iran holds defence drills at nuclear plants: commander & Sunday, 14 November 2010 & AFP \\
\hline 49 & EU accepts Iran talks offer, suggests venue & Friday, 12 November 2010 & AFP \\
\hline 50 & E.U. responds to Iran about talks on nuclear program & Friday, 12 November 2010 & The New York Times \\
\hline
\end{tabular}

\section{Data ANALYsis}

As we mentioned above, the theoretical framework of this article is van Leeuwen's socio-semantic network of social actors and within this framework, we study the representation of Iranian and western actors of nuclear case of Iran. The analysis of the data has shown that international media represent the actors of the two sides of the table in a considerably different way and the inclusion of western actors is much higher than their Iranian counterparts. In this body of data we also observed that even the name of a geographical entity such as the Persian Gulf (the official name which is approved by all of the international organizations for example the United Nations) is reduced to Gulf which shows the political attitudes behind this naming strategy. In the following we will summarize the main findings of the research:

\section{A) inclusion/exclusion mechanisms:}

Analysis of the data showed that leading international media news agencies and newspapers do follow the policy of including the western actors in positive subjects (defending the human rights and international peace) and excluding them from negative subjects. The general picture of the western figures acting in this quarrel is the image of peace- 
seeker and rational persons while the situation is totally different (if not vice versa) for Iranian ones. In many cases we face the extreme exclusion mechanism toward Iranian actors and they are totally or partially omitted in the discourse and are categorized as mass nouns while western actors are active and present in the text and have personal identity for themselves. In the following examples you can see reference to highly prestigious figures who are speaking against Iran's nuclear case while Iranian actors are generally called as Iranian officials or totally omitted. The negative utterances toward Iranian nuclear program are always quoted from "experts", "lawmakers" or even the general and ambiguous source of "analysis". (numbers stands for the title number listed in the table above.)

6- Top US officer says Iran still driving for a bomb.

13- Iran talks were difficult: U.S. official.

24- US lawmakers fume over China's Iran links.

44- Stuxnet study suggests Iran enrichment aim: experts.

45-Analysis: Are Iran nuclear talks doomed to fail again?

48- Iran holds defense drills at nuclear plants: commander.

We also observed that the politically oriented attitude toward the coverage of the news related to this program is significant in quoting from the leaders of those countries such as China and Russia who are usually in the same track with Iran and defend the right of this country to have access to nuclear power:

2-Medvedev says Iran nuclear stance 'unreasonably tough.

22-China says hopes Iran nuclear talks are constructive.

46- China, Russia urge Iran to show nuclear plans peaceful.

Analysis of the data in this research showed that in 83 percent of the news is directly or indirectly quoted from the western actors' point of view and Iranian actors are totally omitted or backgrounded from the text. The only utterance which is reflected from the Iranian side is the cliché sentence of: "Iran rejects all the blames and says its program is peaceful." This sentence does not convey any informative value and the body of the news is written in a way that the readers find it dubious (if not false!)

In some cases, the western media directly and clearly show their attitude toward Iranian actors, for example, in news number one Iranian president is called as the hardliner:

“...President Mahmoud Ahmadinejad, meanwhile, on Tuesday welcomed the upcoming talks in Istanbul, which he said would be followed by rounds of negotiations in Brazil and Iran.

The hardliner said world powers had applied a «lot of political pressure» against Iran and adopted «sanctions one after another to prevent Iran from becoming nuclear.»...” (Iran says no date set for nuclear talks/AFP/ 28 Dec. 2010)

\section{B) Naming strategies:}

As an independent country, Iran has a clear and accepted name in international organizations such as the UN which is "The Islamic Republic of Iran" and should be referred to as Iran or the complete title we mentioned but amazingly we observed that international media tend to name Iran with different discoursively meaningful titles such as: "one of the biggest oil producing countries", Islamic regime/Shiat regime, irresponsible country and so on.

It seems that by calling Iran as a country with the biggest gas and oil resources, the western news agencies are indirectly conveying the message that a country with considerable fossil fuel resources does not have any need to invest on nuclear programs, this claim is not acceptable when Russia, and USA with great fuel resources have the biggest nuclear power plants!

By naming Iran as Islamic regime they seemingly want to relate Iran with the Islamophobic trend of western media. Referring to Iran as a Shiat country is another strategy to illustrate Iran as an isolated country because Iran is the only member of the international community in which Shiat faith is the official religion.

\section{CONCLUSION}

In this article, we studied a body of news related to Iran's nuclear program within CDA approach (van Leeuwen's socio-semantic network of social actors) to see if international news agencies and newspapers reflect social actors of the both sides equally and neutrally or not. The two most prominent mechanisms of inclusion and exclusion are in the center of attention in this paper.

The analysis showed that although international leading media claim that they reflect events and realities without political intentions, there is a clear political and ideological attitudes in covering the news stories and analyses about Iran-US clash on nuclear program.

Western social actors are included in positive actions such as defending the human rights and they are generally illustrated as logical peace seekers. The situation is totally different when Iranian actors are presented, and they are excluded from positive actions or state of affairs and included in negative ones.

The voice of Iranian side is mainly limited to cliché sentences empty from any new information while the western actors are usually introduced as experts and complete analyses are quoted from their point of view.

This article shows that the audience of international mass media should be more clever and have critical thinking about the way media represent the world and events. 
[1] Aghagolzade, F. \& R. Kheirabadi (2008). A linguistic study of news values in Iranian press. The international journal of humanities of the Islamic republic of Iran 15(1), 1-7.

[2] Bell, A. (1991). The language of news media. Oxford: Blackwell.

[3] Fairclough, N. (1988, 2001).Language and Power. London: Routledge.

[4] Fairclough, N. (1992). Discourse and social change. Cambridge: Polity Press.

[5] Fairclough, N. (2003). "Analysing discourse". London: Routledge.

[6] Fairclough;N. (1989,2001). Language and Power. London: Longman.

[7] Fowler, R. (1991). "Language in the news" London: Routledge.

[8] Van Dijk, T. A. (1988). News as discourse. Hillsdale, NJ: L. Erlbaum Associates.

[9] Van Dijk, T. A. (1988). News analysis: Case studies of international and national news in the press. Hillsdale, NJ: Lawrence Erlbaum Associates, Inc.

[10] Van Leeuwen; T. (2008). "Discourse and practice, New tools for critical discourse analysis". Oxford university press.

[11] Van Leeuwen; T. (1993). "Language and Representation: The Recontextualisation of Participants, Activities and Reactions." Unpublished Ph.D. thesis, University of Sydney.

[12] Van Leeuwen; T. (1995). "Representing Social Action,” Discourse and Society 6(1):81-106.

[13] Van Leeuwen; T. (1996). "The Representation of Social Actors." In C. R. Caldas-Coulthard and M. Colthard (Eds.), Text and Practices: Readings in Critical Discourse Analysis (pp.32-70) London: Routledge.

Reza Kheirabadi was born in Tehran, Islamic Republic of Iran in 1979. He has got his PhD of General Linguistics from Tarbiat Modares University (Tehran, Iran) in 2012 and received his M.A. from the same university in 2006.

$\mathrm{He}$ is currently working for Organization for Educational Research and Planning (OERP) which is the official body to prepare textbook materials and curriculum planning in Islamic Republic of Iran. He also has the experience of working for leading Iranian newspapers and news agencies as journalists and translator.

His main research interests are News production process, Language of News, Critical Discourse Analysis of news and ethnographic study of journalistic activities in Iran. His MA thesis was also about linguistic study of news values in press of Iran.

Mr. Kheirabadi is a research assistant of NT\&T and a member of Public Relations Expert Association of Islamic Republic of Iran.

Seyyed Behnam Alavi Moghaddam was born in Khorram Abad, Islamic Republic of Iran in 1975. He has got his PhD of General Linguistics from Allame Tabatabaee University (ATU, Tehran, Iran) in 2008 and received his M.A. from the same university in 2002 and his BA of English teaching (TEFL) from Arak University in 1997.

Now, he is working as a scientific member (assistant professor) in Textbook Preparation Bureau of Organization for Educational Research and Planning (OERP).He is teaching in BA and MA levels too. He has written different books and articles in some fields like bilingualism, language skills, textbook materials etc. 